\title{
Effect of an acute necrotic bacterial gill infection and feed deprivation on the metabolic rate of Atlantic salmon Salmo salar
}

\author{
M. A. Jones*, M. D. Powell, J. A. Becker, C. G. Carter \\ School of Aquaculture, Aquafin CRC, Tasmanian Aquaculture and Fisheries Institute, University of Tasmania, \\ Locked Bag 1370, Launceston, Tasmania 7250, Australia
}

\begin{abstract}
In this study, experiments were conducted to examine the effect of an acute necrotic bacterial gill infection on the metabolic rate $\left(\mathrm{M}_{\mathrm{O}_{2}}\right)$ of Atlantic salmon Salmo salar. Fed and unfed Atlantic salmon smolts were exposed to a high concentration $\left(5 \times 10^{12} \mathrm{CFU} \mathrm{ml}{ }^{-1}\right)$ of the bacteria Tenacibaculum maritimum, their routine and maximum metabolic rates $\left(\mathrm{M}_{\mathrm{O}_{2 \text { rout }}}\right.$ and $\mathrm{M}_{\mathrm{O}_{2 \text { max }}}$ respectively) were measured, and relative metabolic scope determined. A significant decrease in metabolic scope was found for both fed and unfed infected groups. Fed infected fish had a mean \pm standard error of the mean (SEM) decrease of $2.21 \pm 0.97 \mu \mathrm{M} \mathrm{O}_{2} \mathrm{~g}^{-1} \mathrm{~h}^{-1}$, whilst unfed fish a mean $\pm \mathrm{SEM}$ decrease of $3.16 \pm 1.29 \mu \mathrm{M} \mathrm{O}_{2} \mathrm{~g}^{-1} \mathrm{~h}^{-1}$. The decrease in metabolic scope was a result of significantly increased $\mathrm{M}_{\mathrm{O}_{2 \text { rout }}}$ of both fed and unfed infected salmon. Fed infected fish had a mean $\pm \mathrm{SEM}$ increase in $\mathrm{M}_{\mathrm{O}_{2 \text { rout }}}$ of $1.86 \pm 0.66 \mu \mathrm{M} \mathrm{O}_{2} \mathrm{~g}^{-1} \mathrm{~h}^{-1}$, whilst unfed infected fish had a mean $\pm \mathrm{SEM}$ increase of 2.16 $\pm 0.72 \mu \mathrm{M} \mathrm{O}_{2} \mathrm{~g}^{-1} \mathrm{~h}^{-1}$. Interestingly, all groups maintained $\mathrm{M}_{\mathrm{O}_{2 \max }}$ regardless of infection status. Increases in $\mathrm{M}_{\mathrm{O}_{2 \text { rout }}}$ corresponded to a significant increase in blood plasma osmolality. A decrease in metabolic scope has implications for how individuals allocate energy; fish with smaller metabolic scope will have less energy to allocate to functions such as growth, reproduction and immune response, which may adversely affect the efficiency of fish growth.
\end{abstract}

KEY WORDS: Tenacibaculum maritimum • Metabolic rate • Atlantic salmon • Feed ration . Oxygen consumption · Bacteria $\cdot$ Exercise

\section{INTRODUCTION}

Stressors, including disease, impose a metabolic cost on fish that consists of 2 mechanisms: (1) an energy requirement to manage the disturbances associated with the stressor; and (2) an energy cost related to correcting the associated ionoregulatory imbalance (Barton \& Iwama 1991). Measurements of oxygen consumption rates, which are essentially an indirect measurement of metabolic rates $\left(\mathrm{M}_{\mathrm{O}_{2}}\right.$ ) (and will be referred to as such), are used to evaluate the amount of energy an organism is using at any given moment (Jobling 1994). $\mathrm{M}_{\mathrm{O}_{2}}$ of most animals fluctuates between 2 extremes. The lower limit is typically referred to as 'standard' or 'basal' $\mathrm{M}_{\mathrm{O}_{2}}\left(\mathrm{M}_{\mathrm{O}_{2} \text { basal }}\right)$ and is the $\mathrm{M}_{\mathrm{O}_{2}}$ of a quiescent animal in a post-absorptive nutritional state, below which physiological function is impaired (Brett \& Groves 1979, Jobling 1994). However, fish ordinarily expend energy above this level, due to activities such as feeding and locomotion, and this lower level is referred to as 'routine' $\mathrm{M}_{\mathrm{O}_{2}}\left(\mathrm{M}_{\mathrm{O}_{2 \text { rout }}}\right)$. The upper extreme is referred to as 'active' or 'maximum' $\mathrm{M}_{\mathrm{O}_{2}}$ $\left(\mathrm{M}_{\mathrm{O}_{2 \max }}\right)$ and the range through which the aerobic $\mathrm{M}_{\mathrm{O}_{2}}$ can vary is referred to as the 'scope for activity' or 'metabolic scope' $\left(\mathrm{M}_{\mathrm{O}_{2 \max }}\right.$ to $\left.\mathrm{M}_{\mathrm{O}_{2 \text { basal }}}\right)$ (Fry 1947). Alternatively, metabolic scope can be expressed as 'relative metabolic scope,' which is the difference between $\mathrm{M}_{\mathrm{O}_{2 \text { rout }}}$ and $\mathrm{M}_{\mathrm{O}_{2 \max }}$ (Wieser 1985).

$\mathrm{M}_{\mathrm{O}_{2}}$ measurements are highly sensitive and can vary due to a number of factors, including fish size (Hunt von Herbing \& White, 2002), nutritional history of the fish (Jobling 1981, Carter \& Brafield 1991, Shoemaker 
et al. 2003), prior stresses (Lankford et al. 2005), and environmental conditions, such as temperature and salinity (Schurmann \& Steffensen 1997, Morgan \& Iwama 1998). Recent studies have begun to highlight the link between infection status and $\mathrm{M}_{\mathrm{O}^{\prime}}$, suggesting that $\mathrm{M}_{\mathrm{O}_{2}}$ measurements might be an effective tool for quantifying the impact of disease on fish (Wagner et al. 2003, Powell et al. 2005a, Tierney et al. 2005, Wagner et al. 2005). However, the impact of gill diseases on the $\mathrm{M}_{\mathrm{O}_{2}}$ of Atlantic salmon has had little attention. A recent study that examined the effect of amoebic gill disease on Atlantic salmon found that salmon, in response to the disease, had significantly elevated $\mathrm{M}_{\mathrm{O}_{2 \text { rout }}}$ whilst being able to maintain $\mathrm{M}_{\mathrm{O}_{2 \max }}$ despite a perceived reduction in gill surface area (authors' unpubl. data). However, little information exists with regard to the effect that bacterial infections, particularly necrotic bacterial gill infections, have on $\mathrm{M}_{\mathrm{O}_{2}}$ and metabolic scope.

Tenacibaculum maritimum (formerly Flexibacter maritimus) causes a skin infection resulting in ulcerative dermatitis, although gill infections with a necrotizing branchitis are not unusual, with experimental infections progressing similarly to natural infections (Handlinger et al. 1997). This disease affects a number of wild and cultured species including Atlantic salmon Salmo salar, greenback flounder Rhombosolea taprina, striped trumpeter Latris lineata, red sea bream Pagrus major, black seabream Acanthopagrus schegeli, Japanese flounder Paralichthys olivaceus and rock bream Oplegnathus fasciatus (Baxa et al. 1986, Wakabayashi et al. 1986, Handlinger et al. 1997). Atlantic salmon experimentally infected with $T$. maritimum were unable to maintain homeostatic regulation of blood plasma osmolality, resulting in significant increases in blood ion concentration (Powell et al. 2004). In marine teleosts, osmoregulation represents a large proportion of the energy expenditure associated with $\mathrm{M}_{\mathrm{O}_{2 \text { rout }}}$ (Jobling 1994); thus, any disturbance due to disease may significantly increase the $\mathrm{M}_{\mathrm{O}_{\text {2rout }}}$ of a quiescent fish.

The $\mathrm{M}_{\mathrm{O}_{\text {2rout }}}$ of Atlantic salmon has been shown to decrease significantly during periods of feed deprivation ( $\mathrm{O}^{\prime}$ Connor et al. 2000). The reduction in $\mathrm{M}_{\mathrm{O}_{2 \text { rout }}}$ may be due to changes in the biochemical composition of the organs, relative organs weights, changes in protein turnover rates, and reduced immune function (Jobling 1994, Lim \& Klesius 2003). Withholding feed has also been shown to be a successful strategy for disease management for some diseases (Shoemaker et al. 2003). For example, feed-deprived Atlantic salmon had a lower cumulative mortality of $2 \%$ compared to $36 \%$ mortality in fed animals when experimentally challenged with a pathogenic bacteria Vibrio salmonicida (Damsgard et al. 1998). Conversely, feed deprivation has been shown to increase mortality in channel catfish Ictalurus punctatus challenged with the bacteria Edwardsiella ictaluri (Lim \& Klesius 2003) and Flavobacterium columnare (Shoemaker et al. 2003).

The objective of the present study was to determine the combined effects of an acute necrotic bacterial gill infection, using Tenacibaculum maritimum as a model, and nutritional deprivation on $\mathrm{M}_{\mathrm{O}_{2 \text { rout }}}$ and $\mathrm{M}_{\mathrm{O}_{2 \max }}$ and subsequent metabolic scope.

\section{MATERIALS AND METHODS}

Fish husbandry. Atlantic salmon smolts with a mean \pm standard error of the mean (SEM) mass of $68.4 \mathrm{~g} \pm 1.7 \mathrm{~g}$ and a mean \pm SEM fork length of $22.0 \pm 1.1 \mathrm{~cm}$ were obtained from the Saltas freshwater commercial hatchery in Wayatinah, Tasmania, Australia, and acclimated over $2 \mathrm{wk}$ to full strength seawater $(35 \%$, $1 \mu \mathrm{m}$ filtered) at $16^{\circ} \mathrm{C}\left( \pm 1^{\circ} \mathrm{C}\right)$ in a rectangular fibreglass $4000 \mathrm{l}$ Rathbun tank. Previous experiments conducted at this facility have shown that this is a sufficient amount of time to ensure a majority of the fish smolt correctly.

All experiments were conducted in a separate temperature-controlled room $\left(17^{\circ} \mathrm{C}\right)$ that housed 4 individual 4001 recirculation systems. Each system consisted of a $200 \mathrm{l}$ conical bottom tank and a $200 \mathrm{l}$ sump, which contained a biofilter and mesh to remove solids and catch uneaten feed. One hundred salmon (25 per tank) were removed from a holding tank and anesthetized using clove oil $(0.003 \%, 90 \%$ active ingredient eugenol, Langford Sales and Marketing). A 29-gauge needle was used to make a sub-dermal injection of Alcian blue dye into one of 6 defined positions on the abdomen of the fish to enable individual identification, with 16 fish tagged for each tank $\left(\mathrm{O}^{\prime} \mathrm{Connor}\right.$ et al. 2000). All fish were fed for $1 \mathrm{wk}$ in order to establish a feeding response, after which fish in 2 tanks were fed twice daily to apparent satiation for a further $2 \mathrm{wk}$, whilst the fish in the remaining 2 tanks had their feed withheld. Water quality was measured daily throughout the experiment, dissolved oxygen remained above $95 \%$ saturation, total ammonia levels peaked at $2 \mathrm{mg}$ $\mathrm{I}^{-1} 5 \mathrm{~d}$ after transfer from the holding tank to the experimental system and was below $0.5 \mathrm{mg} \mathrm{l}^{-1}$ at the beginning of the first $\mathrm{M}_{\mathrm{O}_{2}}$ measurement.

$\mathbf{M}_{\mathrm{O}_{2}}$ measurements. Pre-inoculation $\mathrm{M}_{\mathrm{O}_{2 \text { rout }}}$ and $\mathrm{M}_{\mathrm{O}_{2 \max }}$ were sampled following the $2 \mathrm{wk}$ feeding or withholding period, and post-inoculation $\mathrm{M}_{\mathrm{O}_{2}}$ was taken $30 \mathrm{~h}$ after inoculation with bacteria (see 'Inoculation' below). Food was withheld for $24 \mathrm{~h}$ prior to $\mathrm{M}_{\mathrm{O}_{2}}$ measurements to ensure that fish were in a post-absorptive state to avoid confounding results with specific dynamic action (Jobling 1994). Fish were placed into respirometry boxes $16 \mathrm{~h}$ prior to measurement. The respirometry boxes were 
connected to 2 separate 1501 recirculation systems, with 9 boxes per system; inlet water into the respirometry boxes was $100 \%$ air saturated.

A thermostatically controlled oxygen electrode (1302 Electrode, Strathkelvin Instruments) connected to a Strathkelvin Instruments model $782 \mathrm{O}_{2}$ meter was calibrated using a $2 \% \mathrm{NaSO}_{3}$ (zero) solution and air saturated seawater (155 $\mathrm{mm} \mathrm{Hg}$ ), prior to the $\mathrm{M}_{\mathrm{O}_{2}}$ measurements. To determine $\mathrm{M}_{\mathrm{O}_{2 \text { rout }}}$ water and airflow to the boxes was halted, and a $3 \mathrm{ml}$ sample of water removed from the box and injected into the oxygen electrode. After $10 \mathrm{~min}$, the water in the box was mixed by pumping the $3 \mathrm{ml}$ syringe 10 times in order to obtain a homogenous water mixture, after which a final water sample was taken and the oxygen content re-measured using the electrode (Powell et al. 2005a).

$\mathrm{M}_{\mathrm{O}_{2 \max }}$ was measured using protocols similar to those found in Cutts et al. (2002). Briefly, individual salmon were removed from respirometry boxes and placed into a 501 cylindrical container that contained hyperoxic seawater $\left(120 \%\right.$ air saturation, $\left.17^{\circ} \mathrm{C}\right)$, and the fish were chased by hand to exhaustion (10 min). Fish were immediately returned to the 11 boxes and their oxygen consumption rate measured (as above). $\mathrm{M}_{\mathrm{O}_{2}}$ was calculated using the following formula:

$$
\mathrm{M}_{\mathrm{O}_{2}}=\frac{\left[\left(\mathrm{pO}_{2_{\mathrm{i}}}-\mathrm{p} O_{2_{\mathrm{e}}}\right) \times \alpha\right] \times V}{T \times M}
$$

where $\mathrm{pO}_{2 \mathrm{i}}$ and $\mathrm{p} \mathrm{O}_{2 \mathrm{e}}$ are the initial and final oxygen partial pressures respectively ( $\mathrm{mm} \mathrm{Hg}$ ), $\alpha$ is the molar $\mathrm{O}_{2}$ solubility in water $\left(\mu \mathrm{M} \mathrm{O}_{2} \mathrm{l}^{-1} \mathrm{~mm} \mathrm{Hg}^{-1}\right), V$ is the respirometer box volume (1), $T$ is the time between the initial and the final oxygen measurements (s) and $M$ is the mass (g) of the fish (Cameron 1986, Cech 1990). Where there was not a complete seal between the airwater interface and the oxygen transfer rates were found to be $0.183 \mathrm{~mm} \mathrm{Hg}$ over a $10 \mathrm{~min}$ period, the results were corrected accordingly. $\mathrm{M}_{\mathrm{O}_{2 \max }}$ was measured immediately after net ammonia excretion rates were determined (see below). $\mathrm{M}_{\mathrm{O}_{2 \text { rout }}}$ and $\mathrm{M}_{\mathrm{O}_{2 \max }}$ and net ammonia excretion rates were re-measured (as described above) $30 \mathrm{~h}$ post-inoculation.

Net ammonia excretion rates. Net ammonia excretion rate measurements were performed between the $\mathrm{M}_{\mathrm{O}_{2 \text { rout }}}$ and $\mathrm{M}_{\mathrm{O}_{2 \max }}$ determinations. Water flow to the respirometer boxes was stopped and a $3 \mathrm{ml}$ water sample was extracted and immediately frozen at $-20^{\circ} \mathrm{C}$. After $1 \mathrm{~h}$ a second water sample was taken, frozen and water flow was resumed. Water samples were analysed using methods described by Verdouw et al. (1978). Excretion rates were calculated using the following formula:

$$
\mathrm{NH}_{4}^{+}{ }_{\text {flux }}=\frac{\left(\left[\mathrm{NH}_{4}^{+}\right]_{\text {final }}-\left[\mathrm{NH}_{4}^{+}\right]_{\text {initial }}\right) \times V}{M}
$$

where $\left[\mathrm{NH}_{4}^{+}\right]$is the concentration of ammonia $\left(\mu \mathrm{mol} \mathrm{l^{-1 }}\right), V$ is the volume (l) of the respirometry box and $M$ is the mass of the fish $(\mathrm{g})$. Air was supplied throughout the experiment with dissolved oxygen levels remaining above $95 \%$ saturation for the duration of the experiment.

Inoculation. Cultures of Tenacibaculum maritimum strain 00/3280 were obtained from cultures held at the Tasmanian Aquaculture and Fisheries Institute (Fish Health Unit, Department of Primary Industries and Water, Tasmania, Australia). Isolates were originally isolated from farmed trout raised in seawater and identified using a $16 \mathrm{~S}$ ribosomal RNA (rRNA) PCR primer set specific for T. maritimum. Cultures were subsequently stored at $-80^{\circ} \mathrm{C}$ on MicroBank beads (Pro-Lab Diagnostics) for later use (Powell et al. 2004). Briefly, $200 \mathrm{ml}$ of Shieh's medium formulated with seawater mineral salts buffer (MSB) was inoculated with $T$. maritimum and gently agitated at $20^{\circ} \mathrm{C}$ for $48 \mathrm{~h}$. The suspension was centrifuged at 2500 relative centrifugal force $(\mathrm{RCF})$, the pellet washed twice and resuspended in $15 \mathrm{ml}$ of sterile seawater, and the bacterial concentration determined by serial dilution. Following the pre-inoculation $\mathrm{M}_{\mathrm{O}_{2 \max }}$ measurement, a $200 \mu \mathrm{l}$ suspension of $T$. maritimum $\left(5 \times 10^{12}\right.$ cells $\left.\mathrm{ml}^{-1}\right)$ was applied evenly over all of the 8 gill arches of the anaesthetised Atlantic salmon (Powell et al. 2004, 2005b). The 00/3280 strain of T. maritimum has been shown to be highly pathogenic to Atlantic salmon at high concentrations in a previous study (Powell et al. 2004). Furthermore, in Powell et al. $(2004,2005 b)$ the infection remained primarily as a gill disease and did not manifest as a skin lesion. As the aim of this particular trial was to use an acute necrotic gill infection as a model for examining the effects on $\mathrm{M}_{\mathrm{O}_{2}}$ it was deemed appropriate to use a high bacterial concentration similar to that previously described (Powell et al. 2004). Furthermore, this allowed for a relative comparison with regard to the physiological effect of infection on the fish with previous studies conducted (Powell et al. 2004, 2005b). Control fish received a saline solution and all fish were returned to their respective tanks. After $30 \mathrm{~h}, \mathrm{M}_{\mathrm{O}_{2 \text { rout }}}, \mathrm{M}_{\mathrm{O}_{2 \max }}$ and net ammonia excretion rates were re-measured (post-inoculation samples) as described above.

Following the post-inoculation $\mathrm{M}_{\mathrm{O}_{2}}$ measurements, fish were given a lethal overdose of clove oil $(0.005 \%)$, weighed and fork length measured. Blood samples $(3 \mathrm{ml}$ ) were taken via a caudal puncture and were centrifuged at 8000 RCF for 2 min using a Spinwin MC-01 (Tarsons Products) and the plasma was decanted and frozen $\left(-20^{\circ} \mathrm{C}\right)$. Blood plasma osmolality was measured using a Wescor Vapro 5520 vapour pressure osmometer (Helena Laboratories). Additionally, a sterile plastic loop was used to sample mucus 
from the gills and plated on Shieh's marine agar to determine the presence of Tenacibaculum maritimum. Cultures were incubated at $20^{\circ} \mathrm{C}$ for $36 \mathrm{~h}$ and colonies were confirmed as T. maritimum by colony colour and shape (Wakabayashi et al. 1986, Powell et al. 2005b). This was considered sufficient as the experiment was following protocols used in Powell et al. (2005b), in which colony colour and shape were used primarily as a means of identifying $T$. maritimum. Furthermore, the aim of this particular experiment was to determine the effect of gill necrosis on $\mathrm{M}_{\mathrm{O}_{2}}$ rather than examining the specific effects of $T$. maritimum per se; therefore, identification past colony shape and colour was deemed unnecessary. The entire gill was excised and rinsed gently in seawater and placed into saltwater Davidson's fixative for $24 \mathrm{~h}$, then into $70 \%$ ethanol for histology (Nowak \& Adams 2003). The entire stomach from the end of the oesophagus to the beginning of the pyloric caeca was removed and placed in $10 \%$ buffered formalin. Twenty-four h following fixation, the internal organs were transferred into $70 \%$ ethanol. The second left anterior gill arch and a thin slice (approximately $3 \mathrm{~mm}$ ) of a centre section of stomach was removed, dehydrated, embedded in paraffin wax, sectioned at $5 \mu \mathrm{m}$ and stained with haematoxylin and eosin (H\&E). Gill sections were then viewed at $100 \times$ magnification for signs of focal branchial lamellar necrosis and associated bacterial mats. Stomach cross-sections were viewed for signs of feed deprivation, such as a thinning of the longitudinal and circular muscle layer and necrosis of the mucosal epithelium.

Statistical analyses. The study was completed in triplicate to obtain statistically significant numbers of fish, so there were 19 fed infected, 8 unfed infected, 11 fed uninfected and 16 unfed uninfected fish in total. Statistical analyses were conducted using the statistical package SPSS for Windows (Version 11.5). A 2-tailed $t$-test was used to determine whether there was a significant difference in change in weight between the fed treatments (infected and uninfected) and the unfed groups. A paired sample $t$-test was used to determine the difference between $\mathrm{M}_{\mathrm{O}_{2 \text { rout }}}$ pre- and post-inoculation for each individual group. A similar analysis was used for $\mathrm{M}_{\mathrm{O}_{2 \max }}$ and metabolic scope. A 1 -way analysis of variance (ANOVA) was used to determine differences in blood plasma osmolality among the 4 groups and significant differences were investigated using a Tukey's post-hoc test. For the ammonia flux, paired sample $t$-tests were used to determine difference between the treatments pre- and post-inoculation. Furthermore, two 1-way ANOVAs were used to determine whether there was a significant difference between the 4 treatments pre-inoculation and post-inoculation.

\section{RESULTS}

Tenacibaculum maritimum putatively diagnosed by colony shape and colour was recovered from all salmon that were exposed to the bacteria and no cultures developed from samples collected from control fish. Infection with $T$. maritimum presented itself as yellowish mucoid patches at the filament tips. Histologically, there was branchial epithelial necrosis, with overlying bacterial mats. Histological examination of the sections of stomach revealed that both fed and unfed groups had signs of feed deprivation that included necrosis of the mucosal epithelium and a general thinning of the longitudinal and circular muscle layers, this was more prevalent in the unfed treatments. Furthermore, fed infected fish in the $\mathrm{M}_{\mathrm{O} 2}$ study lost on average $5.90 \pm 1.65 \mathrm{~g}$ (mean \pm SEM) of their initial mass, whilst unfed infected fish lost $14.6 \pm 1.33 \mathrm{~g}$ (mean $\pm \mathrm{SEM}$ ). For the uninfected treatments the fed group lost an average of $5.93 \pm 1.65 \mathrm{~g}$ (mean \pm SEM) and the unfed group lost an average of $8.61 \pm 2.56 \mathrm{~g}$ (mean \pm SEM). There was no statistical difference between the change in weight of the fed uninfected and fed infected fish $(\mathrm{p}=$ 0.993) and the unfed infected and unfed uninfected fish $(p=0.127)$. However, the unfed infected fish lost significantly more weight than the fed infected fish $(p=0.003)$ as did the unfed uninfected fish when compared to the fed uninfected fish $(p=0.432)$.

Mortalities occurred in all groups, with a majority of the mortality occurring immediately after the initial transfer from the seawater acclimation tanks to the experimental tanks; this was attributed to fish in poor condition that had failed to correctly smolt. However, no mortalities in fish were recorded the week prior to the initial $\mathrm{M}_{\mathrm{O}_{2}}$ measurement.

\section{Metabolic scope and $\mathrm{M}_{\mathrm{O}_{2}}$}

Metabolic scope decreased significantly for fed infected fish from pre- to post-inoculation; the reduction represented an overall decrease of $40 \%$ from pre-inoculation levels ( $p=0.036$, Fig. 1). Also, metabolic scope decreased significantly in the unfed infected group with an overall reduction of $49 \%$ from pre-inoculation levels ( $p=0.04$, Fig. 1). Uninfected groups had no significant change in metabolic scope.

$\mathrm{M}_{\mathrm{O}_{2 \text { rout }}}$ increased significantly from pre- to postinoculation levels in infected salmon that were fed and unfed ( $p=0.01$ and 0.02, respectively, Table 1). Fed infected fish had an average increase in $\mathrm{M}_{\mathrm{O}_{2 \text { rout }}}$ (mean $\pm \mathrm{SEM}$ ) of $1.86 \pm 0.66 \mu \mathrm{M} \mathrm{O}_{2} \mathrm{~g}^{-1} \mathrm{~h}^{-1}$ whilst unfed infected fish had an average increase (mean \pm SEM) of $2.16 \pm 0.72 \mu \mathrm{M} \mathrm{O}_{2} \mathrm{~g}^{-1} \mathrm{~h}^{-1} \cdot \mathrm{M}_{\mathrm{O}_{2 \max }}$ increased significantly for unfed uninfected fish $(\mathrm{p}=0.01$, Table 1) with 


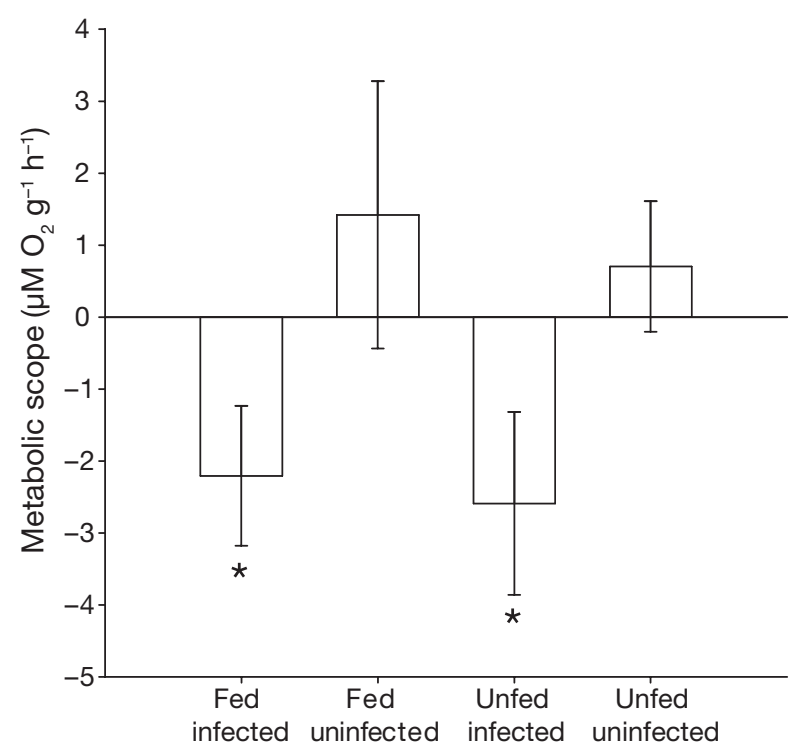

Fig. 1. Salmo salar. Mean $( \pm$ SEM) change in metabolic scope from pre- to post-inoculation of Atlantic salmon exposed to Tenacibaculum maritimum. ${ }^{*}$ Significant change $(\mathrm{p}<0.05)$ in metabolic scope from pre- to post-inoculation

an average increase (mean \pm SEM) of $2.51 \pm 0.61 \mu \mathrm{M}$ $\mathrm{O}_{2} \mathrm{~g}^{-1} \mathrm{~h}^{-1}$, whilst all other treatments maintained $\mathrm{M}_{\mathrm{O}_{2 \max }}$ between pre- and post-inoculation.

\section{Blood plasma osmolality and net ammonia excretion rates}

Both infected fed and unfed salmon had significantly higher blood plasma osmolality than uninfected treatments ( $\mathrm{p}<0.001$, Fig. 2A). There was no significant change in net ammonia excretion rates from pre- to post-inoculation for any of the groups. However, a 1-way ANOVA showed that there was a significant difference amongst the groups pre-inoculation, with fed infected fish having an average net ammonia excretion rate significantly higher than that of the unfed uninfected treatment ( $p=0.03$, Fig. 2B).
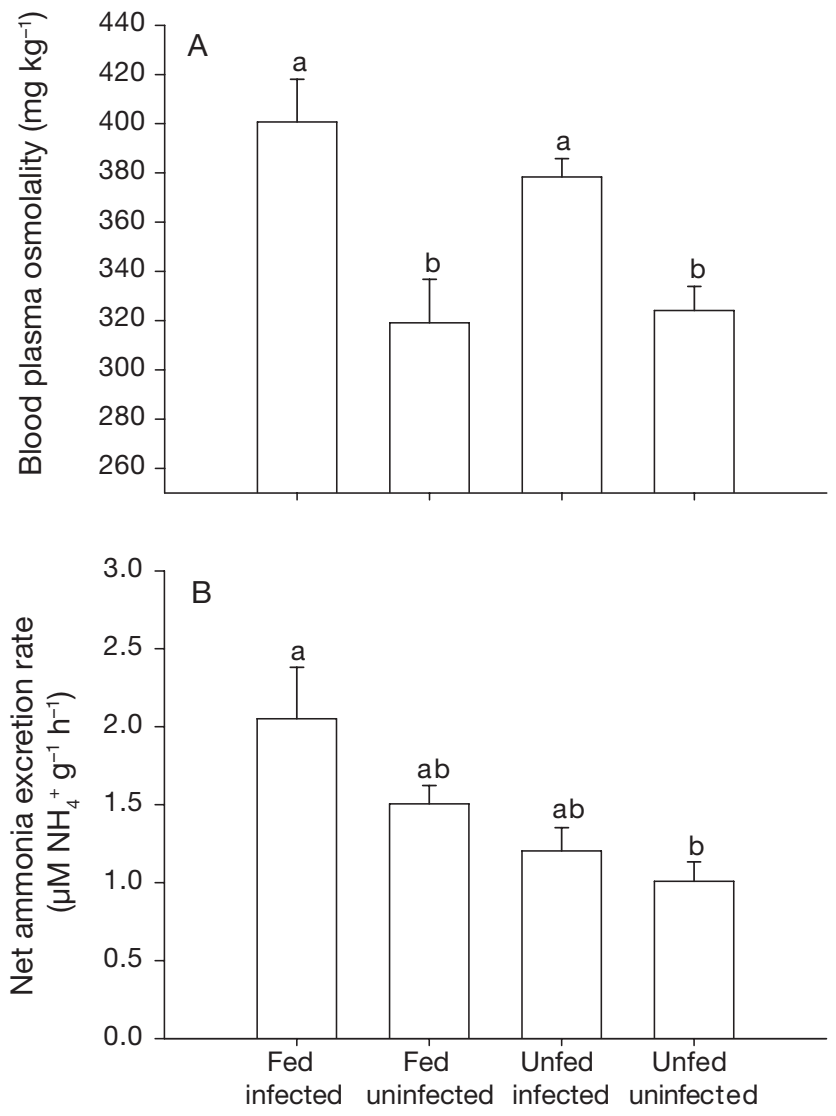

Fig. 2. Salmo salar. (A) Mean $( \pm$ SEM) blood plasma osmolality of fed and unfed Atlantic salmon exposed to Tenacibaculum maritimum. (B) Mean $( \pm$ SEM) net ammonia excretion rates of Atlantic salmon pre- inoculation. Different superscripts indicate a significant difference among treatments

\section{DISCUSSION}

This study was conducted to test the hypothesis that exposing the gill tissue of Atlantic salmon to Tenacibaculum maritimum would result in necrosis of the gill tissue, which would represent a significant additional energetic cost and that this cost could be quantified through changes in $\mathrm{M}_{\mathrm{O}_{2}}$. It was expected that

Table 1. Salmo salar. Mean $( \pm \mathrm{SEM})$ routine $\left(\mathrm{M}_{\mathrm{O}_{2 \text { rout }}}\right)$ and maximum $\left(\mathrm{M}_{\mathrm{O}_{2 \max }}\right)$ metabolic rates $\left(\mu \mathrm{M} \mathrm{O}_{2} \mathrm{~g}^{-1} \mathrm{~h}^{-1}\right)$ pre- and postinoculation for fed and unfed Atlantic salmon. ${ }^{*}$ Significant difference between pre- and post-inoculation levels

\begin{tabular}{|c|c|c|c|c|c|}
\hline & & \multicolumn{2}{|c|}{ Fed } & \multicolumn{2}{|c|}{ Unfed } \\
\hline & & Infected & Uninfected & Infected & Uninfected \\
\hline \multirow[t]{2}{*}{$\mathrm{M}_{\mathrm{O}_{2 \text { rout }}}$} & Pre-inoculation & $5.00 \pm 0.35$ & $6.16 \pm 0.55$ & $5.32 \pm 0.74$ & $4.32 \pm 0.58$ \\
\hline & Post-inoculation & $6.86 \pm 0.54^{*}$ & $5.31 \pm 1.10$ & $7.48 \pm 0.69 * a$ & $5.78 \pm 0.38$ \\
\hline \multirow{2}{*}{$\mathrm{M}_{\mathrm{O}_{2 \max }}$} & Pre-inoculation & $10.53 \pm 0.53$ & $11.32 \pm 0.74$ & $11.08 \pm 1.26$ & $8.37 \pm 0.43$ \\
\hline & Post-inoculation & $10.19 \pm 0.61$ & $11.89 \pm 1.07$ & $10.08 \pm 0.84$ & $10.63 \pm 0.47^{*}$ \\
\hline
\end{tabular}


infected salmon would spend more energy maintaining osmotic homeostasis as a result of the damage to the respiratory and ionoregulatory epithelium of the gills (Powell et al. 2004). The results showed that the variation in 2 consecutive $\mathrm{M}_{\mathrm{O}_{2}}$ measurements on the same individual is small and stable enough to allow comparisons between infected and uninfected fish, thus providing a valuable tool for assessing fish health. The major outcome of this study was that necrosis induced by exposure to $T$. maritimum significantly affected metabolic scope and $\mathrm{M}_{\mathrm{O}_{2 \text { rout }}}$ although infected fish were able to maintain $\mathrm{M}_{\mathrm{O}_{2 \max }}$.

The metabolic scope of Atlantic salmon exposed to Tenacibaculum maritimum was 40 to $49 \%$ (fed and unfed, respectively) of that of control fish, suggesting that fish with a necrotic bacterial gill infection have reduced capacity to perform work (Lankford et al. 2005). Furthermore, prior nutritional status did not appear to significantly affect the level of reduction in metabolic scope. To date, limited research has been published examining the effect of bacterial gill infections on the $\mathrm{M}_{\mathrm{O}_{2}}$ of fish. Of the studies that have focussed primarily on disease and metabolic scope, rainbow trout infected with the parasitic haemoflagellate Cryptobia salmositica showed a $44 \%$ reduction in metabolic scope (Kumaraguru et al. 1995). Alternatively, rainbow trout infected with Loma salmonae successfully maintained metabolic scope by increasing $\mathrm{M}_{\mathrm{O}_{2 \max }}$ whilst brook trout in the same study increased metabolic scope by decreasing $\mathrm{M}_{\mathrm{O}_{2 \text { rout }}}$ (Powell et al. 2005a). A decrease in metabolic scope has implications for energy allocation by individuals; fish with smaller metabolic scope will inevitably have less energy to allocate to functions such as the replenishment of energy stores, growth, reproduction and immune response (Cutts et al. 2002, Lankford et al. 2005).

The decreases in metabolic scope observed in the current study were due to an increase in $\mathrm{M}_{\mathrm{O}_{2 \text { rout }}}$ for the fed and unfed infected treatments. There are a number of possible explanations for the observed increase in $\mathrm{M}_{\mathrm{O}_{\text {2rout }}}$ in infected fish, with the most likely cause being that the additional energy was spent to maintain osmotic homeostasis. This hypothesis was supported by the increase in blood plasma osmolality seen in infected fish. The increase in blood plasma osmolality supports the results found by Powell et al. (2004), in which Atlantic salmon infected by the same strain of Tenacibaculum maritimum had an increase in blood plasma osmolality. It is possible that the increase in $\mathrm{M}_{\mathrm{O}_{2 \text { rout }}}$ was due to an up-regulation of $\mathrm{Na}^{+}, \mathrm{K}^{+}$-ATPase as well as other osmoregulatory organs. $\mathrm{Na}^{+}, \mathrm{K}^{+}$ATPase is the primary enzyme responsible for maintaining osmotic homeostasis; thus, any shift in the osmotic equilibrium may result in a significant up regulation of this particular enzyme (Jobling 1994). How- ever, enzyme activity was not specifically measured in the present study. It is also reasonable to assume that exposure to T. maritimum and the subsequent necrosis elicited a stress response in the fish. Atlantic salmon exposed to $T$. maritimum have significantly elevated plasma lactate levels pre-mortem (Powell et al. 2004) and similar results were found for Chinook salmon Oncorhynchus tshawytscha exposed to Renibacterium salmoninarum, which had significantly increased levels of cortisol and lactate, indicating a stress response to infection (Mesa et al. 2000). Increased lactate and cortisol levels in fish have been shown to directly correlate to increases in $\mathrm{M}_{\mathrm{O}_{2}}$ (Davis \& Schreck 1997). The effect on $\mathrm{M}_{\mathrm{O}_{2 \text { rout }}}$ of the transfer of fish from fresh to salt water $4 \mathrm{wk}$ prior to the first $\mathrm{M}_{\mathrm{O}_{2}}$ measurement is suspected to be minimal, as previous studies have shown only a moderate effect on $\mathrm{M}_{\mathrm{O}_{\text {2rout }}}$ ( \pm 5 to $6 \%$ ) immediately after transfer (Maxime 2002).

$\mathrm{M}_{\mathrm{O}_{2 \max }}$ for infected Atlantic salmon did not change significantly from pre- to post-inoculation levels, suggesting that the increased costs associated with exposure to Tenacibaculum maritimum were not compensated by an increase in $\mathrm{M}_{\mathrm{O}_{2 \max }}$. The results concur with those of Powell et al. (2005a), which found no net change in $\mathrm{M}_{\mathrm{O}_{2 \max }}$ associated with disease in brook trout infected with Loma salmonae, but did find compensatory increases in rainbow trout infected with $L$. salmonae. Necrosis due to exposure to T. maritimum effectively reduces the available surface area for respiration (Powell et al. 2004). There is evidence suggesting that in some fish species a reduction in functional gill area is linked to a reduction in $\mathrm{M}_{\mathrm{O}_{2 \max }}$ (Duthie \& Hughes 1987, Schurmann \& Steffensen 1997). By maintaining $\mathrm{M}_{\mathrm{O}_{2 \max }}$ despite a reduction in functional gill surface area, salmon in the current study may have employed compensatory mechanisms during infection, such as an increased functional surface area of the gills, increasing the permeability of the gill to ions and increased cardiac output (Booth 1979, Gonzalez \& McDonald 1994, Powell et al. 2000). Indeed, salmon infected with $T$. maritimum do not show signs of hypoxemia or a reduced capacity for the transport of oxygen (Powell et al. 2005b). However, as the cardiorespiratory system in salmonids is diffusion-limited, rather than perfusion-limited, any compensatory mechanisms employed must be constrained by the maximum rate that oxygen can be transported through the gill tissue (Powell \& Perry 1999, Gallaugher et al. 2001, Cutts et al. 2002).

Net ammonia flux was shown to be unaffected by disease, which confirmed previous findings (Powell et al. 2004). There was a significant difference between the fed infected and unfed uninfected groups, no significant differences were found for the remaining groups. It was expected that a significant difference 
would be found between all fed and unfed groups; however, it is possible that the $24 \mathrm{~h}$ starvation period prior to measurement that was required for the $\mathrm{M}_{\mathrm{O} 2}$ measurements may have been enough to mitigate the effects of prior feeding. Furthermore, although the fed treatments were supplied with food twice daily to apparent satiation, there was a net decrease in weight over the duration of the experiment, suggesting that some of the fish failed to resume feeding upon transfer into the experimental systems. However, the reduction in weight was minimal and some of this weight loss could be due to the fish not being fed for a total of $48 \mathrm{~h}$ prior to sampling. Furthermore, the unfed treatments lost significantly more weight than the fed treatments, thus making the comparisons between fed and unfed treatments valid.

The key finding in the present study was an observed decline in the maximum metabolic scope for activity in Atlantic salmon exposed to Tenacibaculum maritimum. This was associated with an increase in plasma osmolality, resulting from branchial epithelial necrosis associated with the disease. Interestingly, despite a high degree of necrosis found in the gill tissue, fish maintained $\mathrm{M}_{\mathrm{O}_{2 \max }}$. Reduction in metabolic scope has a number of biological implications, the most important being a reduced ability to allocate energy to more desirable outcomes, such as growth and reproduction, which will have profound implications for efficiency in aquaculture.

Acknowledgements. The authors thank J. Carson for the supply of Tenacibaculum maritimum, J. Ransome and M. Barney and the UTAS AGD research group for technical support. This work formed part of a project of Aquafin CRC, and received funds from the Australian Government's CRC Program, the Fisheries R\&D Corporation and other CRC participants.

\section{LITERATURE CITED}

Adams MB, Nowak BF (2003) Amoebic gill disease: sequential pathology in culture Atlantic salmon, Salmo salar L. J Fish Dis 26:601-614

Barton BA, Iwama GK (1991) Physiological changes in fish from stress in aquaculture with emphasis on the response and effects of corticosteroids. Annu Rev Fish Dis 1:3-26

Baxa DV, Kawai K, Kusuda R (1986) Characteristics of gliding bacteria isolated from diseased cultured flounder, Paralichthys olivaceus. Fish Pathol 21:251-258

Booth JH (1979) Circulation in trout gills: the relationship between branchial perfusion and the width of the lamellar blood space. Can J Zool 57:2183-2185

Brett JR, Groves TDD (1979) Physiological energetics. In: Hoar WS, Randall DJ (eds) Fish physiology, Vol VIII. Academic Press, New York, p 279-352

Cameron JN (1986) Principles of physiological measurements. Academic Press, London

Carter CG, Brafield AE (1991) The bioenergetics of grass carp Ctenopharyngodon idella (Val.): energy allocation at dif- ferent planes of nutrition. J Fish Biol 39:873-887

Cech JJ (1990) Respirometry. In: Schreck CB, Moyle PB (eds) Methods for fish biology. American Fisheries Society, Bethesda, MD, p 335-362

Cutts CJ, Metcalfe NB, Taylor AC (2002) Juvenile Atlantic salmon (Salmo salar) with relatively high standard metabolic rates have small metabolic scopes. Funct Ecol 16:73-78

Damsgard B, Mortensen A, Sommer AI (1998) Effects of infectious pancreatic necrosis virus (IPNV) on appetite and growth in Atlantic salmon, Salmo salar L. Aquaculture 163:183-191

Davis LE, Schreck CB (1997) Energetic response to handling stress in juvenile coho salmon. Trans Am Fish Soc 126: $248-258$

Duthie GC, Hughes GM (1987). The effects of reduced gill area and hyperoxia on the oxygen consumption and swimming speed of rainbow trout. J Exp Biol 127:349-352

Fry FEJ (1947) Effects of the environment on animal activity. Univ Tor Stud Biol Ser 55:1-62

Handlinger J, Soltani M, Percival S (1997) The pathology of Flexibacter maritimus in aquaculture species in Tasmania, Australia. J Fish Dis 20:159-168

Gallaugher PE, Thorarensen H, Kiessling A, Farrell AP (2001) Effects of high intensity exercise training on cardiovascular function, oxygen uptake, internal oxygen transport and osmotic balance in chinook salmon (Oncorhynchus tshawytscha) during critical speed swimming. J Exp Biol 204:2861-2872

Gonzalez RJ, McDonald DG, (1994) The relationship between oxygen uptake and ion loss in fish from diverse habitats. J Exp Biol 190:95-108

Hunt von Herbing I, White L (2002) The effects of body mass and feeding on metabolic rate in small juvenile Atlantic cod. J Fish Biol 61:945-958

Jobling M (1981) The influences of feeding on the metabolic rate of fishes: a short review. J Fish Biol 18:385-400

Jobling M (1994) Fish bioenergetics. Chapman \& Hall, New York

Kumaraguru AK, Beamish FWH, Woo PTK (1995) Impact of a pathogenic haemoflagellate, Crytobia salmositica Katz, on the metabolism and swimming performance of rainbow trout, Oncorhynchus mykiss (Walbaum). J Fish Dis 18: 297-305

Lankford SE, Adams TE, Miller RA, Cech JJ Jr (2005) The cost of chronic stress: impacts of a nonhabituating stress response on metabolic variables and swimming performance in sturgeon. Physiol Biochem Zool 78:599-609

Lim C, Klesius PH (2003) Influence of feed deprivation on hematology, macrophage chemotaxis, and resistance to Edwardsiella ictaluri challenge of channel catfish. J Aquat Anim Health 15:13-20

Maxime V (2002) Effects of transfer to sea water on standard and routine metabolic rates in smolting Atlantic salmon at different stages of seawater adaptability. J Fish Biol 61: 1423-1432

Mesa MG, Maule AG, Schreck (2000) Interaction of infection with Renibacterium salmoninarum and physical stress in juvenile Chinook salmon: physiological responses, disease progression, and mortality. Trans Am Fish Soc 129:158-173

Morgan JD, Iwama GK (1998) Salinity effects on oxygen consumption, gill $\mathrm{Na}, \mathrm{K}-\mathrm{ATP}$ ase and ion regulation in juvenile coho salmon. J Fish Biol 53:1110-1119

O'Connor KI, Taylor AC, Metcalfe NB (2000) The stability of standard metabolic rate during a period of food deprivation in juvenile Atlantic salmon. J Fish Biol 57:41-51

Powell MD, Perry SP (1999) Cardiorespiratory effects of Chloromine $\mathrm{T}$ in rainbow trout. Exp Biol Online 4:5 
Powell MD, Fisk D, Nowak BF (2000) Effects of graded hypoxia on Atlantic salmon infected with amoebic gill disease. J Fish Biol 57:1047-1057

Powell MD, Carson J, van Gelderen R (2004) Experimental induction of gill disease in Atlantic salmon Salmo salar smolts with Tenacibaculum maritimum. Dis Aquat Org 61:179-185

Powell MD, Speare DJ, Daley J, Lovy J (2005a) Differences in metabolic response to Loma salmonae infection in juvenile rainbow trout Oncohynchus mykiss and brook trout Salvlinus fontinalis. Dis Aquat Org 67:233-237

Powell MD, Harris JO, Carson J, Hill JV (2005b) Effects of gill abrasion and experimental infection with Tenacibaculum maritimum on the respiratory physiology of Atlantic salmon Salmo salar affected by amoebic gill disease. Dis Aquat Org 63:169-174

Schurmann H, Steffensen JF (1997) Effects of temperature, hypoxia and activity on the metabolism of juvenile Atlantic cod. J Fish Biol 50:1166-1180

Shoemaker CA, Klesius PH, Lim C, Yildirim M (2003) Feed deprivation of channel catfish, Ictalurus punctatus (Rafinesque), influences organosomatic indices, chemical composition and susceptibility to Flavobacterium columnare.

Editorial responsibility: David Bruno,

Aberdeen, UK
J Fish Dis 26:553-561

Tierney KB, Balfry SK, Farrell AP (2005) Subclinical Listonella anguillarum infection does not impair recovery of swimming performance in rainbow trout Oncorhynchus mykiss. Dis Aquat Org 67:81-86

Verdouw H, van Etcheld CJA, Dekkers EM (1978) Ammonium determinations based upon indophenol formation with sodium salicylate. Water Res 12:399-402

Wagner GN, McKinley RS, Bjoern PA, Finstad B (2003) Physiological impact of sea lice on swimming performance of Atlantic salmon. J Fish Biol 62:1000-1009

Wagner GN, Hinch SG, Kuchel LJ, Lotto A and 10 others (2005) Metabolic rates and swimming performance of adult Fraser River sockeye salmon (Oncorhynchus nerka) after a controlled infection with Parvicapsula minibicornis. Can J Fish Aquat Sci 62:2124-2133

Wakabayashi H, Hikida M, Masumura K (1986) Flexibacter infection in cultured marine fish in Japan. Helgol Meeresunters 37:587-593

Wieser W (1985) Developmental and metabolic constraints of the scope for activity in young rainbow trout (Salmo gairdneri). J Exp Biol 118:133-142

Submitted: October 30, 2006; Accepted: July 24, 2007 Proofs received from author(s): October 24, 2007 